\title{
Evaluation of Biomass Briquetting Mechanism
}

\author{
Edgars Repsa, Eriks Kronbergs, Andris Kronbergs \\ Latvia University of Agriculture, Faculty of Engineering, Institute of Mechanics. \\ Address: J. Cakstes bulv. 5, Jelgava, LV-3001, Latvia
}

\begin{abstract}
The main task of this investigation is evaluation of patented (LV 14604 B) biomass briquetting mechanism. Theoretical relationship between necessary drive force and resistance force during pressing in die was determined.

Briquettes from grinded common reed (Phragmites Australis) or common reed - peat mixture were produced with designed experimental briquetting press. Density of common reed briquettes depending on the size of particles was stated. Density of briquettes obtained during compacting was from $826.3 \pm 16.4$ to $934.5 \pm 35.1 \mathrm{~kg} \mathrm{~m}^{-3}$. The minimum of density $826.3 \pm 16.4 \mathrm{~kg} \mathrm{~m}^{-3}$ had briquettes with particles from $6 \mathrm{~mm}$ grinding screen, but maximum density $934.5 \pm 35.1 \mathrm{~kg} \mathrm{~m}^{-3}$ had briquettes, when particles from $1.5 \mathrm{~mm}$ grinding screen had been used. Compositions of reed particles with peat allow obtaining briquettes density $>1000 \mathrm{~kg} \mathrm{~m}^{-3}$ if peat proportion in mixture is $30 \%$.

Results of theoretical and experimental investigation show that the designed pressing mechanism can be recommended for mobile biomass briquetter design.
\end{abstract}

Keywords - briquetting mechanisms, common reed briquetting.

\section{INTRODUCTION}

Firewood, agricultural straws, and energy crops are the most prominent biomass energy sources. In Latvia, approximately $14.6 \%$ [1] of unfarmed agricultural land can be used for herbaceous energy crop growing.

Herbaceous energy crops would be the main basis for solid biofuel production in agricultural ecosystem in future.

Herbaceous energy crops - reed canary grass (Phalaris arundinacea) and hemp (Cannabis sativa) are grown in recent years. Beside that there is possibility to utilize for bioenergy production natural biomass of common reeds overgrowing shorelines of Latvian more than 2000 lakes.

The major limitation of using biomass for energy purposes is it low bulk density, typically ranging from 80 to $150 \mathrm{~kg} \mathrm{~m}^{-3}$ for straw material. Therefore compacting of biomass is important process for effective handling, transport and storage of this fuel material. Low bulk density also makes difficulties in feeding the fuel into the boiler and reduces burning efficiencies.

Peat can be used as additive for manufacturing of solid biofuel, because it improves density, durability of stalk material briquettes (pellets) and avoid corrosion of boilers. More than 230 million tons of peat is available for biofuel production in Latvia.

The aim of this paper is theoretical and experimental evaluation of patented (LV 14604 B) briquetting mechanism. Typical compacting equipment's are classified into the following categories based on their working principles: piston press, screw press, roller press and pelletizer. In this investigation is presented piston press with rhomb mechanism drive.

The presented rhomb mechanism can be used where overcome of large resistance with a small driving force is necessary.

\section{MATERIALS AND METHODS}

Relationship between necessary drive force and resistance force during pressing in die was expressed using virtual work theory [2]. Scheme of rhomb mechanism is shown in Fig. 1.

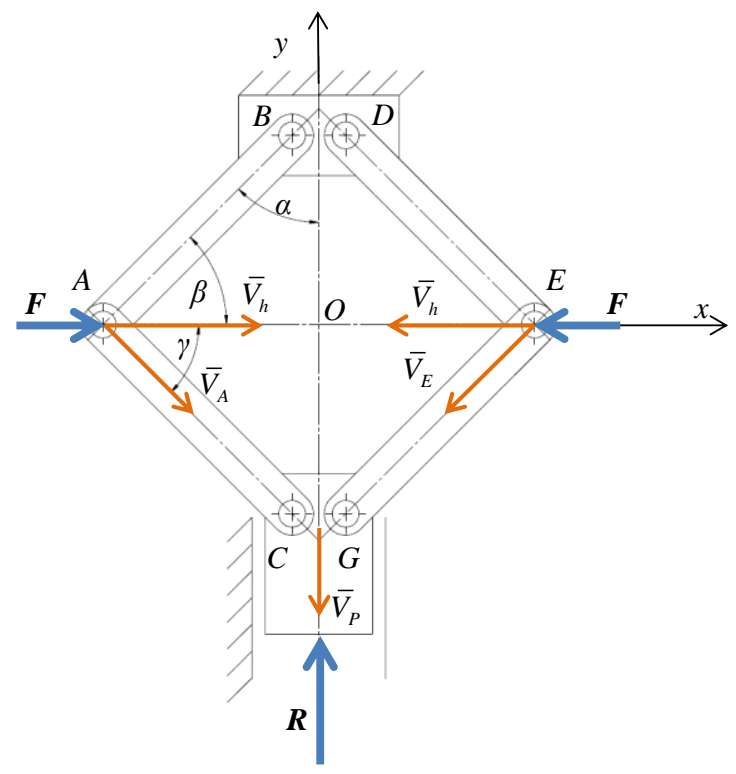

Fig. 1. Scheme of briquetting mechanism

Notes: $A B, D E, E G, A C$ - links of mechanism; $\alpha$ - angle between mechanism link and y-axis; $\beta$ - angle between mechanism link and $x$-axis; $\gamma-$ angle between velocity vectors $\bar{V}_{A}$ and $\bar{V}_{h}$; $\bar{V}_{A}$ - velocity vector of point $A ; \bar{V}_{E}-$ velocity vector of point $E$; $\bar{V}_{h}-$ velocity vector of hydraulic cylinder displacement; $\bar{V}_{P}-$ velocity vector of mechanism piston; $F-$ drive force; $R$ - reaction force in pressing die.

For reaction force $R$ calculation power equation can be used

$$
F \bar{V}_{h}=R \bar{V}_{P} .
$$


Mathematical relationship between velocity vectors is

$$
\begin{gathered}
\bar{V}_{h}=\bar{V}_{A} \cos \gamma+\bar{V}_{E} \sin \gamma \\
\bar{V}_{P}=2 \bar{V}_{A} \sin \gamma=2 \bar{V}_{E} \sin \gamma
\end{gathered}
$$

From equation (3) expressed $\bar{V}_{A}$ and $\bar{V}_{E}$

$$
\bar{V}_{A}=\frac{\bar{V}_{P}}{2 \sin \gamma} ; \bar{V}_{E}=\frac{\bar{V}_{P}}{2 \sin \gamma} .
$$

Replacing $\bar{V}_{A}$ and $\bar{V}_{E}$ in equation (2)

$$
\bar{V}_{h}=\frac{\cos \gamma \bar{V}_{P}}{2 \sin \gamma}+\frac{\cos \gamma \bar{V}_{P}}{2 \sin \gamma}=\frac{\bar{V}_{P}}{\tan \gamma} .
$$

From equation (1) unknown reaction force in briquetting die

$$
R=\frac{F \bar{V}_{h}}{\bar{V}_{P}}=\frac{F \bar{V}_{P}}{\bar{V}_{P} \tan \gamma}=\frac{F}{\tan \gamma} .
$$

Experimental briquetting press is shown in Fig. 2.

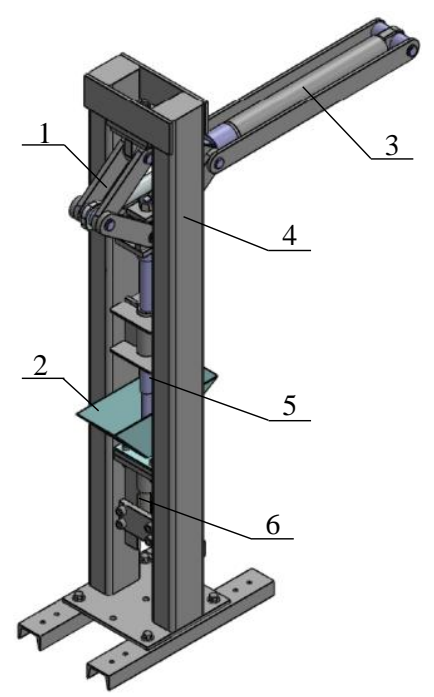

Fig. 2. Briquetting press

Notes: 1 - pressing mechanism; 2 - container; 3 - hydraulic cylinder; 4 - frame; 5 - pressing piston; 6 - pressing die.

Pressing mechanism (1) links size are $200 \mathrm{~mm}$. Pressing die diameter $25 \mathrm{~mm}$. Piston stroke $175 \mathrm{~mm}$. With experimental briquetting press briquettes were made continuously in conical die. For pressing mechanism drive hydraulic cylinder with piston diameter $60 \mathrm{~mm}$ was used.

During briquetting experiments hydraulic pressure was measured with calibrated pressure sensor. For data collection was used Pico Data Logger and computer.

For briquetting experiments grinded common reeds was used. Grinding of common reed was realized with hammer mill using four different screen opening sizes $1.5,6,12$ and $20 \mathrm{~mm}$.

With aim to increase the density and mechanical durability of briquettes, common reed and peat mixtures was used. Peat proportion in mixture was 15 , 30 and $50 \%$.

Moisture of experimental material was less than $10 \%$. The moisture content was determined according the standard BS EN 14774-2:2009, where oven drying of the samples was carried out at $105 \pm 2{ }^{\circ} \mathrm{C}$ [3].

The briquettes with different density had been obtained as result. Briquette density was determined from the ratio of the mass to the volume of the briquette. The weight of briquette was measured on electronic scales Sartorius GM312 with division 0.01 $\mathrm{g}$ and size of briquettes was measured with sliding calipers (division $0.1 \mathrm{~mm}$ ).

European countries have standards (ŌNORM 7135, SS 187120 and DIN 5173 [4, 5] concerned with properties of wood pellets and briquettes. Demand of mentioned biofuel density is $>1000 \mathrm{~kg} \mathrm{~m}^{-3}$ in standards. For lower quality biomass solid fuel permissible density is $>900 \mathrm{~kg} \mathrm{~m}^{-3}$.

Results of briquetting experiments were evaluated on bases of mentioned standards.

\section{RESULTS AND DISCUSSION}

During briquetting experiments hydraulic pressure was measured with calibrated pressure sensor. Example of briquetting pressure dependence on time is shown in Fig. 3.

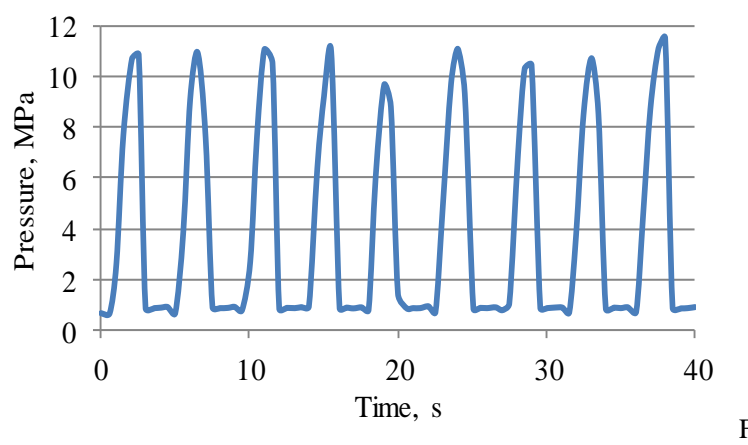

ig. 3. Briquetting pressure diagram

The maximal pressure values for all types of pressing material were recorded from briquetting pressure diagrams. Average values of maximal pressure are shown in Table 1.

Expressions in Table 1: S, 1.5; S, 6; S, 12; S, 20 common reed particles from grinding screen opening sizes 1.5, 6, 12 and $20 \mathrm{~mm}$ accordingly. P15, P30 and P50 - peat additive proportion $15 \%, 30 \%$ and $50 \%$ accordingly.

Average maximal pressure values in rhomb mechanism drive cylinder from 9.14 $\mathrm{MPa}$ to 10.82 $\mathrm{MPa}$ show dependence on particle size and characteristics of briquetting material. 
TABLE 1

MAXIMAL PRESSURE AVERAGE VALUES

\begin{tabular}{|c|c|c|c|c|c|c|c|}
\hline & \multicolumn{7}{|c|}{ Type of pressing material } \\
\hline & $\begin{array}{l}\mathrm{S}, \\
1.5\end{array}$ & S, 6 & $\begin{array}{l}\mathrm{S}, \\
12\end{array}$ & $\begin{array}{l}\mathrm{S}, \\
20\end{array}$ & $\begin{array}{c}\text { S6 } \\
\text { P15 }\end{array}$ & $\begin{array}{c}\text { S6 } \\
\text { P30 }\end{array}$ & $\begin{array}{c}\text { S6 } \\
\text { P50 }\end{array}$ \\
\hline 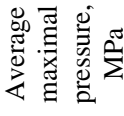 & $\begin{array}{l}\text { ô } \\
\stackrel{0}{0}\end{array}$ & $\begin{array}{l}\circ \\
\infty \\
a\end{array}$ & $\frac{+}{a}$ & $\begin{array}{l}\circ \\
\stackrel{0}{0}\end{array}$ & $\stackrel{\text { సે }}{\stackrel{0}{0}}$ & $\stackrel{0}{\stackrel{0}{0}}$ & $\frac{ \pm}{a}$ \\
\hline 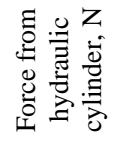 & 요 & $\underset{⿱}{\stackrel{ \pm}{*}}$ & 气ิ & 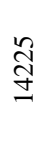 & $\frac{0}{6}$ & $\begin{array}{l}\text { ఫे } \\
\infty \\
\stackrel{n}{n}\end{array}$ & $\begin{array}{l}\stackrel{0}{\sim} \\
\stackrel{\sim}{ \pm}\end{array}$ \\
\hline
\end{tabular}

For pressing mechanism theoretical evaluation measured maximal pressure was converted to force of hydraulic cylinder. Calculated pressing forces $\mathrm{R}$, corresponding to maximal drive force $F=15 \mathrm{kN}$, using equation (6) are shown in Fig. 4.

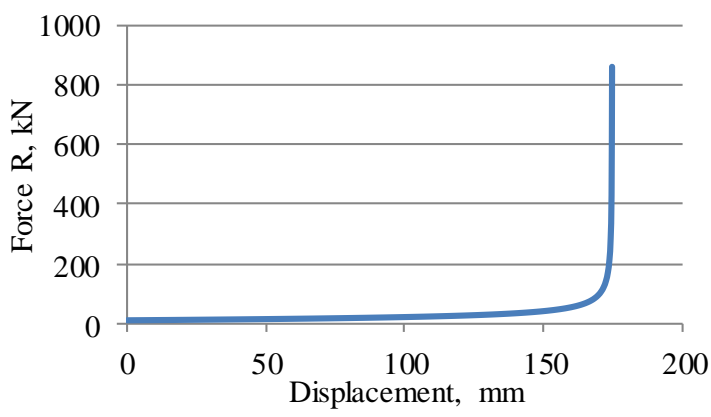

Fig. 4. Pressing mechanism force - displacement characteristic

The presented pressing mechanism piston force displacement characteristics are nonlinear curves with two quasilinear parts. Calculated results show that designed pressing mechanism is able develop much bigger pressing force $R(800 \mathrm{kN})$ comparing with drive force $F(15 \mathrm{kN})$.

The briquettes from four common reed particle groups were produced using designed briquetting press with rhomb mechanism. For particle group's characterization four different screen opening sizes 1.5, 6, 12 and $20 \mathrm{~mm}$ of hammer mill was used. Experimentally obtained density results are shown in Fig. 5 depending on grinding screen opening sizes of particles. Density is the most important parameter in briquetting. The higher the density, the higher is the energy volume ratio.

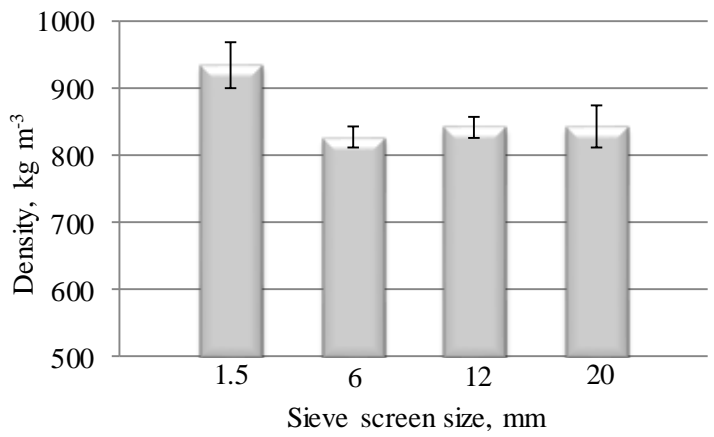

Average density of experimental briquettes was $934.5 \pm 35.1 \mathrm{~kg} \mathrm{~m}^{-3}$ (screen opening size $1.5 \mathrm{~mm}$ ), $826.3 \pm 16.4 \mathrm{~kg} \mathrm{~m}^{-3}$ (screen opening size $6 \mathrm{~mm}$ ), $841.5 \pm 16.5 \mathrm{~kg} \mathrm{~m}^{-3}$ (screen opening size $12 \mathrm{~mm}$ ), $842.2 \pm 31.9 \mathrm{~kg} \mathrm{~m}^{-3}$ (screen opening size $20 \mathrm{~mm}$ ). The briquettes of common reed particles from grinding screen opening size $1.5 \mathrm{~mm}$ let obtain density $>900 \mathrm{~kg} \mathrm{~m}^{-3}$, recommended in EU standards for wood briquettes. The density non-linear change depending on particle size can be explained by particle orientation in die with diameter $25 \mathrm{~mm}$.

Common reed particles with one size group (screen opening size $6 \mathrm{~mm}$ ) were used for composition with different proportion of peat $(15,30$ and $50 \%)$. Briquettes density and mechanical durability can be improved with peat additive in densification. Fig. 6 shows peat proportion influence on common reeds briquette density.

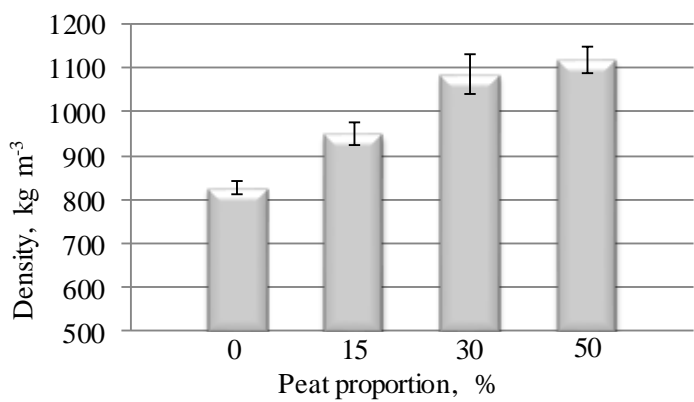

Fig. 6. Common reed - peat mixture briquettes average density

Fig. 6 shows that the briquettes average density increase from $826.3 \pm 16.4$ to $1118.2 \pm 30.9 \mathrm{~kg} \mathrm{~m}^{-3}$ if peat proportion in mixture increases up to $50 \%$. The density of common reed particles and peat mixture briquettes larger than $900 \mathrm{~kg} \mathrm{~m}^{-3}$ has been obtained then peat proportion is $>15 \%$ in composition.

In Fig. 7 and Fig. 8 are shown a photo of produced common reed briquettes.

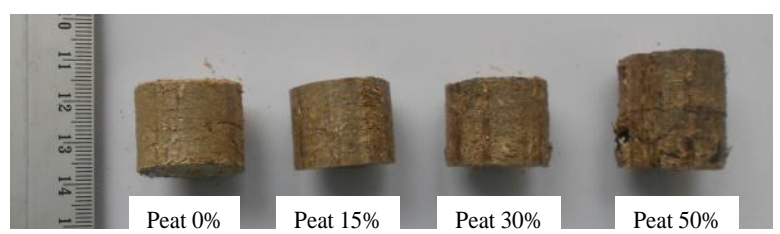

Fig. 7. Common reed briquettes

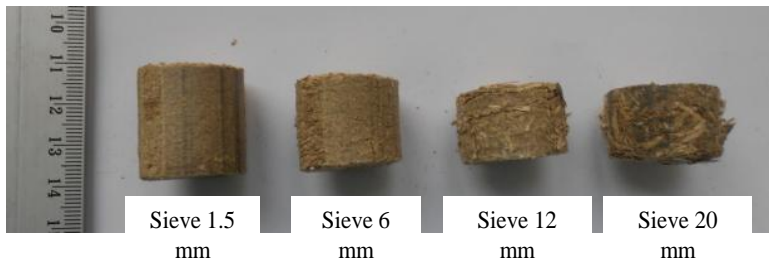

Fig. 8. Common reed and peat mixture briquettes

Notes: Common reed particles from grinding screen opening size $6 \mathrm{~mm}$.

Fig. 5. Common reed briquettes average density 
These experimental briquettes with diameter $25 \mathrm{~mm}$ can be classified also as pellets and used appropriately for heating.

The designed rhomb pressing mechanism can be recommended for biomass briquetting with drive from tractor hydraulic system with pressure $<20 \mathrm{MPa}$ in rural conditions.

\section{CONCLUSION}

Average maximal pressure values in rhomb mechanism drive cylinder from $9.14 \mathrm{MPa}$ to 10.82 $\mathrm{MPa}$ show dependence on particle size and characteristics of briquetting material.

The presented pressing mechanism piston force displacement characteristics are nonlinear curves with two quasilinear parts. Calculated results show that designed pressing mechanism is able develop much bigger pressing force $R(800 \mathrm{kN})$ comparing with drive force $F(15 \mathrm{kN})$.

Average density of experimental briquettes was $934.5 \pm 35.1 \mathrm{~kg} \mathrm{~m}^{-3}$ (screen opening size $1.5 \mathrm{~mm}$ ), $826.3 \pm 16.4 \mathrm{~kg} \mathrm{~m}^{-3}$ (screen opening size $6 \mathrm{~mm}$ ), $841.5 \pm 16.5 \mathrm{~kg} \mathrm{~m}^{-3}$ (screen opening size $12 \mathrm{~mm}$ ), $842.2 \pm 31.9 \mathrm{~kg} \mathrm{~m}^{-3}$ (screen opening size $20 \mathrm{~mm}$ ). The density non-linear change depending on particle size can be explained by particle orientation in die with diameter $25 \mathrm{~mm}$.

The briquettes of common reed particles from grinding screen opening size $1.5 \mathrm{~mm}$ let obtain density $>900 \mathrm{~kg} \mathrm{~m}^{-3}$, recommended in EU standards for wood briquettes.
The briquettes average density increase from $826.3 \pm 16.4$ to $1118.2 \pm 30.9 \mathrm{~kg} \mathrm{~m}^{-3}$ if peat proportion in mixture increases up to $50 \%$. The density of common reed particles and peat mixture briquettes larger than $900 \mathrm{~kg} \mathrm{~m}^{-3}$ has been obtained then peat proportion is $>15 \%$ in composition.

The designed rhomb pressing mechanism can be recommended for biomass briquetting with drive from tractor hydraulic system with pressure $<20 \mathrm{MPa}$ in rural conditions.

\section{ACKNOWLEDGMENTS}

This publication has been prepared within the framework of the ERAF Project „Development of mechanization equipment for energy crops conditioning", $\quad$ contract $\mathrm{Nr}$. 2010/0306/2DP/2.1.1.1.0/10/APIA/VIAA/128.

\section{REFERENCES}

[1] Land politics statement for years 2008. - 2014. The Order of the Cabinet of Ministers of the Republic of Latvia Nr. 613 (in Latvian), http://www.mk.gov.lv, (Accessed on 20.02.2013).

[2] R.M. Dreizler, C. S. Ludde. Theoretical Mechanics: Theoretical Physics 1. New York: Springer, 2011, 412 p. ISBN978-3-642-11137-2.

[3] BS EN 14774-2:2009: Solid biofuels Determination of moisture content - Oven dry method - Part 2: Total moisture Simplified method.

[4] E. Alakangas. European standards for fuel specification and classes of solid biofuels. In Grammelis P. (ed.): Solid biofuel for energy: lower greenhouse gas alternative. Springer, New York, 2011, pp. 21-41. ISSN1865-3529.

[5] M. Matúš, P. Križan. Influence of structural parameters in compacting process on quality of biomass pressings. Journal of applied mathematics. Volume 3, Number 3, 2010, p. 87 - 96. 